Faculty of Education

Te Kura Toi Tangata

Waikato Journal of Education

Te Hautaka Mātauranga o Waikato

Volume 16, Issue 2: 2011 


\section{WAIKATO JOURNAL OF EDUCATION TE HAUTAKA MĀTAURANGA O WAIKATO}

\section{Editors:}

Jane Strachan

Noeline Wright

\author{
Editorial Board: \\ Beverley Bell \\ Bronwen Cowie \\ Deborah Fraser \\ Margie Hohepa \\ Sally Peters \\ Noeline Wright
}

\author{
Margaret Carr \\ Rosemary DeLuca \\ Richard Hill \\ Judy Moreland \\ Clive Pope
}

Waikato Journal of Education is a refereed journal, published annually, based in the Faculty of Education, The University of Waikato, Hamilton, New Zealand. It publishes articles in the broad field of education. For further information visit the WJE website http://edlinked.soe.waikato.ac.nz/research/journal/index.php?id=8

Correspondence and articles for review should be addressed to: Research Manager, Wilf Malcolm Institute of Educational Research, Faculty of Education, The University of Waikato, Private Bag 3105, Hamilton, 3240, New Zealand. Email: wmier@waikato.ac.nz

Business correspondence: Orders, subscription payments and other enquiries should be sent to the Administrator, Waikato Journal of Education, Wilf Malcolm Institute of Educational Research, Faculty of Education, The University of Waikato, Private Bag 3105, Hamilton, 3240, New Zealand, Email: wmier@waikato.ac.nz

Subscriptions: Within NZ \$40; Overseas NZ \$50

Copyright: (C) Faculty of Education, The University of Waikato

Publisher: $\quad$ Faculty of Education, The University of Waikato

Cover design: Donn Ratana

Printed by: Waikato Print

\section{Call for papers}

The Waikato Journal of Education provides an avenue of publication for quality articles on education. This peer-reviewed journal welcomes a range of topics including interdisciplinary, philosophical and applied research approaches.

Submissions are now invited for consideration for publication in the November 2012 issue. Please submit an electronic copy and a separate page with author/s contact details by 30 April 2012 to WMIER Research Manager, Carolyn Jones (cjjones@waikato.ac.nz), Faculty of Education, University of Waikato, Private Bag 3105, Hamilton 3240, New Zealand. 


\section{Waikato Journal of Education}

\section{Te Hautaka Mātauranga o Waikato}

Volume 16, Issue 2: 2011

\section{Special Edition: A teacher education partnership between the Solomon Islands and New Zealand}

Editorial

The Solomon Islands School of Education Partnership: Aspirations, context and design in educational change

Clive McGee and Patricia Rodie

Partnership experiences in developing the Preparation for Tertiary Learning course in the Teachers in Training programme

Roselyn Maneipuri, Immaculate Runialo and Noeline Wright

Making sense of health education in the Solomon Islands

Kirsten Petrie and Mark Tehe

The Solomon Islands mathematics: Pedagogy in transition?

Nigel Calder, John Beuka and Calvin Ngatulu

Taking ownership: The story of a successful partnership for change in a Pacific Island science teacher education setting

Richard Edwards, Solomon Pita and James Porakari

Funds of knowledge: Developing a Diploma in Teaching in Early Childhood Education in the Solomon Islands

Janette Kelly, Joanna Daiwo and Viola Malasa

Weaving a "Hybrid Mat": Samoa meets the Solomons

Barbara Whyte

Sustaining organisational change: Teacher education in the Solomon Islands Jane Strachan, Susanne Maezama and Janine Simi

Exploring factors that influence school planning in community high schools in the Solomon Islands: Principals' perspectives

Samuel Aruhu and David Giles

Experiences of being a leader in Choiseul Province: Opening principals' and deputy principals' contexts of leadership

John Sisiolo and David Giles

Book review 


Waikato Journal of Education
Te Hautaka Mātauranga o
Volume 16 Issue 2: 2011

\title{
Making sense of health education in the Solomon Islands
}

\section{Kirsten Petrie}

Faculty of Education, The University of Waikato

\section{Mark Tehe}

School of Education,

Solomon Islands College for Higher Education

\begin{abstract}
This article explores both the process and outcomes of a working Partnership between Solomon Islands College for Higher Education and the University of Waikato that explored the development of the initial teacher education health education courses. Through a process of co-construction and inquiry, teacher educators from the Solomon Islands and New Zealand developed a metaphorical context-specific model to represent understandings of health education in the Solomon Islands. The model and what this has meant for teaching and learning in health education at both SOE and in schools is examined.
\end{abstract}

\section{Keywords}

Solomon Islands, health education, partnership, teacher education.

\section{Introduction}

During three weeks in 2008 and 2009, we (Kirsten and Mark, along with Patrick Miniti and Silas Lui) worked together to develop health education courses for initial teacher education (ITE) students attending the Solomon Islands School of Education (SOE) to align the courses with diploma and degree standard qualifications. As health education is a compulsory part of the Solomon Islands school curriculum, all ITE students preparing to work in primary schools are required to complete a compulsory course consisting of 20 hours face to face, while those who were opting to teach health education in secondary schools complete a whole semester course, the equivalent of 90 hours face to face. In this paper, we briefly examine three elements: what it meant for

Faculty of Education, University of Waikato, Hamilton, New Zealand

ISSN: 1173-6135

(pp. 31-42) 
us to work in partnership to develop the required courses, exploring what it meant to develop a context-specific health education programme, and outlining outcomes of our revised "curriculum".

\section{Ways of working in partnership}

Three weeks was a very short timeframe in which to design a context-specific health education programme. As health educators, we recognised that before we could make progress on our specified task, we first needed to dedicate time to building a respectful relationship and developing a shared understanding of health education. For me (Kirsten), the international partner, it was also necessary to develop an understanding of the Solomon Islands context and explore culturally sensitive/appropriate ways of working with my Solomon Islands colleagues. Given the lack of context-specific (or even Pasifika-specific) materials to support understandings of, or the teaching of, health education, it was apparent that local expertise was essential to ensure that an appropriate programme was developed.

As the local counterpart for developing the health education course, I (Mark) was excited that I finally had someone to work with on developing the course. Working with a female may have challenged many of my colleagues, due to the nature of our culturally specific gender relations; however, my previous experience as a nurse really helped me get along well with Kirsten. Understanding and being culturally sensitive is a two-way process. While there were expectations that Kirsten should act in certain ways, I too felt that it was appropriate that I should understand her cultural way of being, so that our relationship was mutually culturally responsive and respectful.

It seemed that throughout the process we both embodied many of the attitudes and skills that we would also advocate should be developed in a good health education programme. Recognising our differences and similarities allowed us to establish a joyous environment and working partnership that gave us both space to learn from each other, develop a health education programme, and, importantly, enjoy many laughs. As part of our way of working we created opportunities to share expertise, learn, develop new knowledge, and challenge existing understandings. The expertise held by SOE staff provided valuable insider knowledge, and as the visitor, my knowledge of expectations of degree level qualifications alongside experiences teaching health education contributed an alternative perspective. "Capitalising on both sets of expertise meant that 'expert positions' were taken from time to time" (Fraser, Henderson, \& Price, 2006, p. 59) by each partner. Neither expertise had more value and acknowledging the strengths of both partners was essential to the respectful partnership that we built. Given the sensitive and somewhat intimate nature of much of the health education content, building a relationship that allowed for open, honest and respectful dialogue became essential. At the same time, it reflected an approach that we wanted to carry into our own health education classes. This began with a familiarisation with the health landscape of the Solomon Islands.

\section{Health and health education}

A vital part of the process was making sense of the Solomon Islands' health and health education landscape in order to ensure that both the SOE's health education programme and what teachers taught in schools were context and community specific. 
The health issues for those living in urbanised Honiara vary greatly from those living in rural island communities. Eighty-four percent of people in the Solomon Islands live in rural areas (Bourke, McGregor, Evans, Mullen, \& Pollard, 2006), the vast majority of whom derive their living from subsistence agriculture and smallincome generating activities, such as market gardening. Food is sourced from what they can grow, barter, breed and catch. Rice and fish form a large part of the overall staple diet. Those that live in urbanised Honiara have increased access to pre-packaged refined foods, which has significantly altered their traditional diet. The Health Promotion Division, Ministry of Health and Medical Services has raised awareness of the importance of eating more fruits and vegetables, and is due to release dietary guidelines as a part of a national campaign to improve the dietary habits of the population. Early childhood classes contribute to this awareness by singing songs such as "Kaikai Pawpaw", "Shake, Shake the Mango Tree" and "Jesus, Give Us Fruits for Our Daily Needs". Whilst the awareness level is high, it appears to have very little impact on individuals, families and communities, as the actual planting and eating of five or more vegetables is hindered by lack of employment, low income and land disputes.

A range of organisations (such as NZAID, 2009; Family Planning, n.d; Save the Children, n.d) have reported on the medical status of Solomon Islands communities. This research highlights how environmental issues, such as poor sanitation, access to clean water, medical care, toilets, and adequate rubbish disposal are problematic throughout the Solomon Islands, and accentuated in the urbanised area of Honiara. World Vision (n.d.) lists the major causes of ill health and death in the Solomon Islands as infectious, communicable diseases, such as malaria, acute respiratory infections and pneumonia. Malaria is a critical public health problem despite more than 30 years of intensive efforts to bring it under control.

A visitor travelling to the Solomon Islands is made acutely aware of some of the required precautionary measures to protect against dengue fever and malaria. The billboards that greet visitors to Honiara remind of the dangers of HIV and the need to practise "Abstinence, Be faithful, and use Condoms (ABC)" (taken from a billboard outside the Honiara Football Stadium) in response to emerging concerns about the high rates of sexually transmitted infections (STIs), and HIV and AIDS. Solomon Islands communities appear to be highly vulnerable to HIV and STIs, linked to poor awareness of sexual reproductive health, low levels of condom use, high levels of violence against women, high fertility rates, and high levels of teenage pregnancy.

Drawing on a more holistic view of health, recent research has reported high instances of alcoholism, depression, violence against others and suicide. Jourdan (2008) recommended that the

Ministry of Education in consultation with Ministry of Health, community services and agencies, develop and introduce into the curriculum information sessions, in schools and their communities, on the psychosocial dimensions of mental health issues such as depression, substance abuse, suicide, bullying and violence and sexual abuse. Schools are seen in the report as a means to educate, however many young people are not enrolled. (p. 42)

Social issues associated with domestic violence, gender issues, living conditions (squatters, overcrowding, wanton ${ }^{\mathrm{i}}$ ), alcohol and drug issues (including a high prevalence of betel nut addiction), racial/ethnic/religious issues, and hetero-normative ${ }^{\text {ii }}$ 
attitudes appear to be factors that accentuate the health issues for Solomon Islanders. The different demands of kastom ${ }^{\text {iii }}$ and modernity create an underlying tension that is difficult for both Solomon Islanders and visitors to negotiate. For example, it is recognised that HIV is a significant issue for Solomon Islands communities, and while there is access to free condoms, this is often not an option due to short supplies and the stigma/religious kastom associated with homosexuality, and premarital sex.

It is in this complex health landscape that teachers in schools are to deliver a health curriculum that will support young Solomon Islanders to develop skills that will allow them to maintain good health.

\section{Health education curriculum}

Health education in school and community settings is seen as a vehicle through which learners have opportunities to develop knowledge skills and attitudes that will help them address/reduce/avoid many of the health issues that they face. Acknowledgement (based on international studies) of the demands high levels of disease place on communities' resources, and the general population's lack of knowledge and skills for avoiding preventable diseases, forced the government to make health education a compulsory part of the school curriculum. There was hope that having learnt about disease prevention at school, children would educate their parents and their peers in their homes. The elevation of health education to compulsory status contributed to the review and redevelopment of the health education curriculum for primary (Year 4 to 6) and secondary (Year 7 to 9) schools. Although there is now access to free education and enrolments are increasing, less than $75 \%$ of children attend primary school, with less than $50 \%$ completing high school (Solomon Islands National Statistics Office, 2005), so the expectations that health education alone will address broader community health issues appears to be unrealistic.

Developed in conjunction with international "experts" funded by aid projects, and given the focus on disease prevention, a medicalised view of health (Tasker, 1996/97) appears to have dominated the Solomon Islands school curriculum. This is demonstrated in the draft of the health curriculum (Solomon Islands Curriculum Development Office, 2009), which is centred on basic first aid, water safety (as in drinking water not aquatics), reproductive health, safe food preparation and the "right foods". This approach to health education is reinforced in the Solomon Islands Primary Health Education Year 4 Learner's Book (Solomon Islands Curriculum Development Centre, 2009), where activities focus on food and personal hygiene, preventing sexual abuse (a big call for primary school students), accessing and maintaining "clean" water, preventing mosquito-transmitted diseases, minimising use of tobacco and betel nut, and information about healthcare services. Health education has been presented as an opportunity to provide students with facts and some knowledge that may minimise their chance of getting physically ill. This conceptualisation of health education was also reflected in the nature and content of the programme delivered as part of the ITE courses.

While these aspects of health reflect many issues young people in the Solomon Islands face, our (Mark, Kirsten, Patrick and Silas) conversations highlighted a range of factors that did not appear to have been considered or addressed in the development of such programmes. It seemed that in order to develop a teacher education curriculum, we needed to consider a range of factors: firstly, more than what was currently presented as 
health education in schools; secondly, recognise the contextual diversity that existed within and across Solomon Islands' communities; and thirdly, the complex factors that impact on individual and community health. We recognised that future teachers need to develop the knowledge, skills and understandings to support diverse learners across the communities they would be working in. The teachers we were responsible for preparing in their ITE programme, would eventually work across a wide range of Solomon Islands' communities. While most would work in rural schools, they would also be supporting students to develop skills to live in urban communities when they got older. Few ITE graduates would have the opportunity to remain in Honiara.

\section{Broadening understandings of the health education}

Early discussions highlighted an ongoing/growing dissatisfaction with the narrow and at times "colonised" or "sanitised" view of health that had been adopted and delivered in the name of health education. For previous aid workers (curriculum experts) "employed" to support curriculum development, it may have been easier to develop a health education programme based on an already developed curriculum, especially if they were familiar with it, such as the Health and Physical Education in New Zealand Curriculum (Ministry of Education, 1999). Such an approach was now inconceivable, given the vast difference between the health landscape of New Zealand and the Solomon Islands, the complexity of the Solomon Islands context, and the unique and varied needs of the community.

This meant that much of our three weeks together as partners was spent engaged in a series of discussions about: the complex interplay of factors-social, economic, domestic, political and cultural-that impact on the health of the Solomon Islands people/community; what this meant for young people (now and in the future) in terms of health; and, therefore, what the nature, purpose and content of an ITE health education programme should be.

These discussions, involving questions (mainly from Kirsten) and context-specific sense-making (Mark, Patrick and Silas), allowed for us to co-construct our understandings of health. This led to imagining what a good health education programme for young people in the Solomon Islands would look like. Questions such as what does health education look, sound, and feel like in the Solomon Islands, and what might you like it to be, generated much deliberation and discussion. Central to this was a feeling that much of the existing teaching and learning did not address the broader social issues that impact on health, the kastoms, attitudes, and the shift, particularly in urbanised Honiara, from collective community care toward more individualistic attitudes. So as we worked through a series of thought-provoking activities, we became convinced that there was a need to progress from the medicalised, disease prevention views of health education programmes dominant until the early 1990s toward a more socio-ecological and holistic approach to health education.

The socio-ecological perspective is a central concept in the Health and Physical Education in the New Zealand Curriculum (Ministry of Education, 1999), framed by the works of Lawson (1992) and Jewett (1994). As detailed by Tasker (1996/97, 2004) a socio-ecological approach to health recognises the complex interconnections between the environment (social, cultural economic, spatial, and physical) and individuals, and acknowledges that individuals do not operate in a vacuum. This requires that the curriculum does more than simply deliver facts on how to prevent diseases (as is 
viewed as accepted practice in a medicalised approach), but instead balances the needs of individuals with encouraging them to engage in "self-reflection, critical thinking and critical action ... to create societal conditions conducive to health for all" (Tasker, 2004, p. 207) members of their community. This approach was then considered for the Solomon Islands context. An example of how this socio-ecological approach may be applied in context would be promoting a different way of approaching disease prevention. In other words, instead of advocating for abstinence as a way to reduce STIs and HIV, the "don't have sex out of wedlock" approach, students would explore what social/cultural kastoms contribute to high rates of these infections, and explore ways that they could take action to bring about change. We collectively felt that such an approach might be more meaningful since it could be directly linked to the Solomon Islands context.

Alongside a socio-ecological approach, it was equally vital to broaden notions of what constitutes health. While we (those developing the programme) understood health from a holistic perspective, it was evident that for most in the Solomon Islands communities, the physical aspects of well-being had been a dominant focus. Traditionally in education, little attention had been paid to the spiritual, social, and mental aspects of well-being. So, understanding the interrelated nature of these dimensions, along with the physical, was seen as essential if we wanted to make a difference to the health of the population of the Solomon Islands through the ITE programmes we developed.

The outcome of these discussions was a revised statement about the goal of a health education programme, which read: Preparing young people in the Solomon Islands with the knowledge, skills and attitudes to create a healthy future for themselves and others. In line with this new vision was a complete reconceptualisation of what should be addressed in a health education programme, across early childhood education, primary and secondary schooling.

\section{The loekan ${ }^{\text {iv }}$ chair model}

It was determined that the loekan chair (see Figure 1) was a useful metaphor to represent our new vision/philosophy for health education in the Solomon Islands (M. Tehe, personal communication, April 1, 2007). The loekan chair can be found in different contexts throughout the Islands, accommodating a range of individuals, just as a good health education programme should.

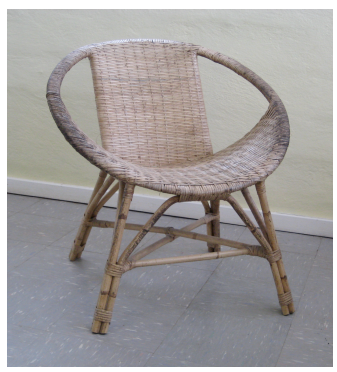

Figure 1. Loekan chair 
Each part of the chair represents a facet of health education:

- The four chair legs represent the dimensions of well-being. These being physical, social, spiritual and emotional/mental;

- Impacting on well-being are the determinants of health: economic, political, environmental, kastom/cultural traditions, each of which are represented by the cross braces;

- The woven parts of the chair (the seat and the back rest) represent the concept of developing life skills (vertical strips) across a range of content areas (horizontal strips). The life skills include: decision-making/problem-solving, communication, caring for self and others, questioning (including taken-forgranted assumptions/kastom), accepting and respecting diversity, dealing with pressure/stress/conflict, and health promotion/critical action. These are to be explored/developed in content areas including community health, drug education, relationships with others, body care and physical safety, and mental health;

- The circular frame of chair represents the pulling together of all the components to make a good health education programme; and finally

- The holes between the back and arms of the chair are seen as the gaps in students' views and understandings of health, and the challenge for teachers to cover it all. They are a reminder to be creative.

In this model the teacher is the weaver, innovator, role model and learner. The teacher is challenged to weave together content and life skills that best reflect the needs of the students in their school community, which will differ across contexts. This means that the teacher needs to be innovative, because it is likely that no two health education programmes would be identical, given the local variations in each community. Teachers are also asked to be role models, where they take action to support the well-being of others and model behaviours such as respecting diversity, which they also expect students to demonstrate. Finally, and as important, teachers are challenged to be learners, who endeavour to seek out opportunities to develop their own understandings.

This loekan chair model was shared with the health education development officer from the Curriculum Development Division (CDD), as there was some anxiety that our new version went beyond how health education had been conceptualised in the national curriculum. As the CDD was in the process of reviewing the health curriculum for schools, we felt that there was potential to influence the outcomes of the final curriculum statements. It appears that resources such as time and money are current barriers to this new health education model being adopted, as it would be expensive to provide professional development for all teachers, and change the resources that are already available to support schools. These barriers are minor compared with the levels of understanding of this model and approach by the CDD officers. However, the loekan chair model and associated "new" understandings of health caused the CDD to reengage in reviewing the current learners' books. It also ensured that they involved SOE staff, health education and PE lecturers in the development of the CDD materials. These developments have the potential to ensure that health education is aligned from early childhood through to tertiary settings. 


\section{Supporting future teachers}

Having developed a coherent philosophy of health education, we then had to design ITE courses that (a) helped teacher education students make sense of this new version of health education, (b) developed the necessary pedagogical content knowledge, and (c) ensured that they felt confident to teach it. We realised we needed to balance the needs of the students as learners of health from a personal perspective, and learners focusing on how to teach health. What was challenging about this was finding ways to support students to reflect on their own understandings, attitudes, values, and roles in relation to their own and others' health. At the same time it was essential to provide opportunities for them to experience this alternative version of health education as learners, and in doing so develop their own understanding of what it means to maintain and enhance their own and others' health. It was also recognised that such an approach to health education would challenge teachers to move beyond transmitting facts, and alter the traditional teacher-centred approaches by adopting much more student-centred and critical pedagogies.

This is a challenge as much for those charged with teaching in the ITE course as it will be for the ITE students. This meant we had to be very explicit about the content of the course, while still allowing for some flexibility. It was also essential that we ensured that the course was pitched at an appropriate level for the qualification. As we worked through the planning of the courses, we explored ways to use readings, in-class activities, and assessment tasks to "cover the content" and allow students to experience it as both learner and future teacher.

While it is not within the scope of this paper to provide a detailed outline of the course, the broad topics detailed in the bullets below provide some sense of what was covered in our endeavour to provide ITE students with the knowledge, skills and attitudes to both enhance their own well-being, and that of their students and others in their teaching communities. Topics addressed included:

- understandings of health and health education, their own experiences and a new way, the aims of school-based health education in the Solomon Islands, and the loekan chair model;

- community health, and undertaking a critical socio-cultural analysis of the Solomon Islands health context;

- the breadth of content areas, and what life skills might be most appropriate to develop in relation to what content area;

- knowing your students and designing context-specific and needs-based programmes that meet their needs, including how to plan both for lessons, units and, longer term, schoolwide;

- strategies for creating positive learning environments that allow health education content to be addressed sensitively and inclusively, with a focus on moving toward student-centred approaches, using role-plays, research, scenarios etc.;

- health promotion, taking critical action to bring about change in your school and community, and supporting students to do the same; and

- the broader role of the health teacher, being a role model, and an advocate for health and health-enhancing practices in the school and community. 
It is important to recognise that the students in the ITE programme are representative of the Solomon Islands' community. This means that many (if not most) live and will eventually work in communities (situations) that have all the "health" issues described above. Many will not have access to clean running water or even reliable electricity. Many live in conditions that are overcrowded, where money is tight, and social issues are prevalent. So when we are asking ITE student teachers to bring about change for the young people they teach, we are actually asking them to first take action to change their own lives and living conditions. This is an extremely challenging position to put students in, particularly when we are asking them to confront the realities of their lives and therefore question accepted kastoms and practices. Hence, it was equally important that lecturers fully understood the sensitivity of the content and associated tasks, so that they could create learning environments in their own classes that were inclusive, accepting of diversity, and safe for all students to participate freely.

\section{How has it gone? A personal reflection}

I (Mark) know in my heart, every time I walk into the classroom that things will be different. The loekan chair metaphor has helped the lecturers to approach the health education course in a holistic manner. In the past, the course addressed only one aspect of health education, the physical. This meant that our students had understood health only from the physical sense and we were simply reinforcing all the messages about health that are "pushed" on us in the wider community.

Now we see students (and lecturers) engaging in conversations about all the dimensions of health, and the determinants. This has tested students' previous conceptions of health and health education. Once they got their heads around a more holistic and socio-cultural perspective, students started to identify for themselves (sometimes with a little prompting) what content areas they needed to cover. We recognise that how teachers define "health" determines how they behave in the classroom. Those who are still only interested in the physical aspects of health appear to be inclined to adopt more traditional teaching approaches, and as lecturers we are exploring ways to move them beyond this.

What has been really exciting has been how the content and the delivery of the courses have changed the classroom environment. The shift from teacher-directed, transmission models of teaching to the use of more student-centred approaches has meant that the classrooms now are noisier and alive. Where once we were inclined to deposit the facts, we now work more as facilitators who contribute ideas, asking questions that challenge student thinking, and allowing students to be the leaders of the learning. Pooling knowledge and skills has made the wealth of knowledge richer. The social aspects of the loekan chair model have provoked lecturers to see the importance of interaction between teacher and learner. The "social disease" that caused distance or a gap between teacher and learner, and between student and student is now healed as we work to ensure that we create a positive and inclusive learning environment. Students, like us as lecturers, have started to understand how to use different pedagogical approaches (role-plays, group work) and teaching styles (direct through to divergent discovery) that allow us to support the development of knowledge, skills and attitudes to create a healthy future for themselves and others. The teacher trainees now can assess themselves and inform the lecturer of what they have learned, their difficulties, and questions for which they need answers. There is always immediate feedback to each 
learner in every health education class, which has really made a difference in the learning, and helped the students see how they might assess in formative ways in their own classroom.

As students engage in life skills activities we frequently hear comments such as "Really, I didn't know that" and "I could use this...". It appears that they are learning the life skills for themselves as well as exploring ways to support young Solomon Islands school students to develop such skills. This dual focus, on them the learner and them the teacher, seems to make the course more relevant for them personally and acts as an entry point for the teaching and learning about the full breadth of content areas. We, students and lecturers, all recognise the challenges associated with bringing about change in a village let alone the wider community. Nevertheless, we have made a start and students in the secondary course have been engaging in health promotion projects on campus.

As with any programme, we are consistently fine-tuning and making changes to address the needs of our ITE students, alongside variations that have developed as we, as teacher educators, have better come to understand the new course and the pedagogical approaches necessary to deliver it. Throughout this experience I have been reminded that we are all learners and working in culturally and contextually respectful partnerships is one way that we can work towards enhancing both health education programmes and practice and, in the long term, the health landscape of the Solomon Islands.

\section{Where to from here?}

Since the introduction of the new course in 2007, there have been ongoing challenges in implementing a holistic approach to health education, both in and beyond the ITE programme. There is a sense that the pre-service students who are learning this new approach will appreciate, accept and apply the modern way of teaching health in their schools. However, the senior teachers these students end up working with may feel threatened by their lack of knowledge and skills and try to remain in the old medical model, limiting opportunities for beginning teachers to try to teach health education differently. In order to change practices in schools, there is an accompanying need to help curriculum development officers expand their knowledge. Without further shifts in their understanding, we will continue to see health education materials that only explore the medical aspects of health. In contrast, we feel it is necessary for the development and distribution of materials and resources that support teachers to understand and incorporate a holistic understanding of well-being into their health education programmes.

Alongside this, there is a need to provide ongoing professional learning for all teachers responsible for the delivery of health education (both in Honiara and in the provinces). However, currently there are limited opportunities for teachers in the Solomon Islands to engage in further professional development once they have completed their ITE qualification. Without ongoing support, and against the backdrop of public health messages centred primarily on the physical aspects of well-being, the adoption and sustainability of the loekan chair model of health education is limited.

While we can look to the education of others as an important step towards changing practice, this will only occur if we, as teacher educators, continue to explore and 
develop our own understandings and practices. Therefore, it is crucial, as we continue to learn ourselves, that we too are provided with opportunities to engage in professional learning, as and beyond what we experienced as partners in the process of developing this new course.

Finally, this approach gives us hope and a way forward to support young people in the Solomon Islands with the knowledge, skills and attitudes to create a healthy future for themselves and others. With continued support, it is our hope that the graduates of SOE will become agents of change as they spread this new model throughout the country.

\section{References}

Bourke, R., McGregor, A., Allen, M., Evans, B., Mullen, B., Pollard, A. et al. (2006). Solomon Islands smallholder agriculture study. Canberra, ACT, Australia: Commonwealth of Australia.

Family Planning. (n.d.). MISHIM - Solomon Islands: Men improving sexual health in Malaita. Retrieved January 14, 2011, from www.fpi.org.nz/what_we_do/projects/mishim___solomon_islands

Fraser, D., Henderson, C., \& Price, G. (2006). The art of the matter: The development and extension of ways of knowing in the arts. Teaching and Learning Research Initiative. Wellington, New Zealand: NZCER.

Jewett, A. E. (1994). Curriculum theory and research in sport pedagogy. Sport Science Review, 3(1), 56-72.

Jourdan, C. (2008). Youth and mental health in Solomon Islands: A situation analysis: tingting helti, tingting siki! Suva, Fiji: Foundation of the Peoples of the South Pacific International.

Lawson, H. A. (1992). Towards a socio-ecological conception of health. Quest, 44, $105-121$.

Ministry of Education. (1999). Health and physical education in the New Zealand curriculum. Wellington, New Zealand: Learning Media.

New Zealand Aid Programme (NZAID). (2009). New Zealand/Solomon Islands programme strategy 2009-2018. Retrieved January 14, 2011, from http://www.aid.govt.nz/library/docs/strategy-solomon-islands-2009-2018.pdf

Solomon Islands Curriculum Development Office. (2009). Solomon Islands health education curriculum - Draft. Honiara, Solomon Islands: Author.

Solomon Islands Curriculum Development Centre. (2009). Solomon Islands primary health education year 4 learner's book. Port Melbourne, VIC, Australia: Pearson Education Australia.

Solomon Islands National Statistics Office. (2005). Social statistics. Honiara, Solomon Islands: Author. Retrieved February 20, 2011, from http://www.spc.int/prism/country/sb/stats/Social/Soc-Index.htm

Save the Children. (n.d.). Solomon Islands HIV \& STI Prevention Project. Fitzroy VIC, Australia: Author. Retrieved January 14, 2011, from www.savethechildren.org.au/sitemap.html

Tasker, G. (1996/97). For whose benefit? The politics of developing a health education curriculum. Delta, 48(2), 187-202.

Tasker, G. (2004). Health education: Contributing to a just society through curriculum change. In A. O’Neill, C. J. Andres, \& O. Roger (Eds.), Reshaping culture, 
knowledge and learning: Policy and content in the New Zealand curriculum framework (pp. 203-223). Palmerston North, New Zealand: Dunmore Press.

World Vision. (n.d.). Major issues facing Solomon Islands. Retrieved from World Vision Pacific Development Group website:

www.pacific.wvasiapacific.org/solomon-islands/62

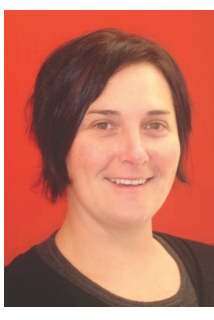

Kirsten Petrie currently teaches in an initial teacher education programme (primary) and the Bachelor of Sport and Leisure Studies in the Faculty of Education, The University of Waikato. Her teaching and research interests include health and physical education curriculum and pedagogy specifically as it relates to primary schooling, and teacher learning (pre- and in-service) and professional development. Her role in the Partnership involved working with SI colleagues to develop the primary and secondary health and physical education courses.

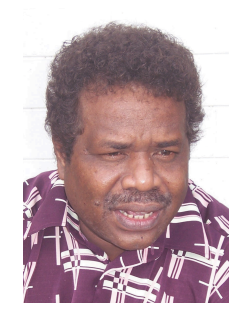

Mark Tehe originally trained as a nurse and then as a teacher. He has also completed a Master in Public Health and became a Director in the Ministry of Health, Solomon Islands. He has been teaching health education at the School of Education, in the Solomon Islands since 2004. Currently he is the team leader of the Distance and Flexible learning teacher education programme .

\footnotetext{
Member of "extended" family — comes with obligation to support wantoks by providing accommodation, financial support.

ii A view that privileges heterosexuality and shuns (oppresses) diversity in relation to sexual orientation.

iii Kastom is a pidjin word used to refer to traditional culture, including religion, economics, art and magic in Melanesia.

iv Loekan is a cane material that is used throughout the Solomon Islands for the construction of furniture and baskets, amongst other things.
} 